\title{
ANALISIS PENGEMBANGAN BUSINESS MODEL CANVAS DALAM UPAYA MENINGKATKAN KEUNGGULAN BERSAING PT. XYZ.
}

\author{
Budiarto \\ Program Studi Magister Manajemen Universitas Tarumanagara \\ mr.budiarto@gmail.com
}

\begin{abstract}
The purpose of this research is to analyze various opportunities and threats obtained from the external environment and various strengths and weaknesses that PT XYZ has obtained from the internal environment which can be a reference for determining the company's business strategy. The external environment covers the general environment (macro) by using PESTEL Analysis (political, economy, social, technology, environment, legal) and also the industrial environment, using the Five Forces Porter analysis. The internal environment uses Core Competencies analysis with the VRCN criteria (Valuable, Rare, Costly to Imitate, Non-Substitutable). The combination of analyst results obtained from the external environment and internal environment will be able to provide an overview of the company's condition which will be simplified by the SWOT Matrix method and the Strategic Generic Porter. It is suggested that PT XYZ conducts market penetration outside the IPC group by developing end-to-end supply chain management product solutions by offering new model business patterns such as revenue sharing and manage operation by making product innovations that are in line with current technological needs.
\end{abstract}

Abstrak : Tujuan dari penelitian ini adalah untuk menganalisis berbagai peluang dan ancaman yang diperoleh dari lingkungan eksternal dan berbagai kekuatan dan kelemahan yang diperoleh PT XYZ dari lingkungan internal yang dapat menjadi acuan untuk menentukan strategi bisnis perusahaan. Lingkungan eksternal meliputi lingkungan umum (makro) dengan menggunakan Analisis PESTEL (politik, ekonomi, sosial, teknologi, lingkungan, hukum) dan juga lingkungan industri, menggunakan analisis Five Forces Porter. Lingkungan internal menggunakan analisis Kompetensi Inti dengan kriteria VRCN (Valuable, Rare, Costly to Imitate, Non-Substitutable). Kombinasi hasil analis yang diperoleh dari lingkungan eksternal dan lingkungan internal akan dapat memberikan gambaran tentang kondisi perusahaan yang akan disederhanakan dengan metode Matriks SWOT dan Strategic Generic Porter. Disarankan agar PT XYZ melakukan penetrasi pasar di luar grup IPC dengan mengembangkan solusi produk manajemen rantai pasok end-to-end dengan menawarkan pola bisnis model baru seperti pembagian pendapatan dan mengelola operasi dengan membuat inovasi produk yang sesuai dengan kebutuhan teknologi saat ini.

Keywords : PESTEL, Porter's Five Forces, Core Competence, VRCN, SWOT, Strategic Generic Porter, Business Model Canvas

\section{PENDAHULUAN}

Dengan perkembangan teknologi yang semakin pesat dan semakin meningkatnya kecepatan arus informasi akibat globalisasi menyebabkan peranan Information Communication Technology (ICT) menjadi vital dan menentukan bagi suatu perusahaan, sehingga intensitas persaingan bisnis penyedia layanan ICT meningkat. Persaingan sangat penting bagi keberhasilan atau kegagalan suatu perusahaan (Porter, 2007) sehingga perusahaan harus dapat menciptakan model bisnis yang memuaskan konsumen agar dapat memenangkan persaingan. Pada kesempatan ini penulis akan meneliti salah satu perusahaan yang menyediakan layanan ICT didalam industri logistik dan kepelabuhanan yaitu PT. XYZ, 
yaitu perusahaan yang memberikan total solusi ICT kepada komunitas logistik mulai dari pertukaran dokumen elektronis dan informasi, integrasi sistem logistik, menyediakan sistem untuk kegiatan operasional di unit-unit pelabuhan seperti terminal, gudang dan kapal serta menyediakan sistem informasi pembayaran elektronik untuk jasa kepelabuhanan. Dalam upaya untuk memenangkan perasaingan, PT XYZ dituntut untuk terus melakukan inovasi dalam bersaing dan menawarkan nilai tambah kepada pelanggan. Untuk itu PT XYZ harus mencari strategi baru untuk menghasilkan suatu model bisnis yang inovatif dan kompetitif untuk dapat menghasilkan laba yang optimal dengan memenangkan persaingan pasar dalam industri ICT. Analisis internal terhadap perusahaan PT XYZ untuk mencari kompetensi inti yang dapat dimanfaatkan untuk memaksimalkan kekuatan serta meminimalisasi kelemahan yang dimiliki. Analisis strategi bisnis yang akan diteliti penulis melalui analisis usulan solusi dengan matriks SWOT dan analisis strategi generik Porter, untuk proses pembuatan rekomendasi bisnis model kanvas yang bertujuan agar perusahaan dapat memperoleh laba secara lebih optimal.

\section{TINJAUAN PUSTAKA}

Manajemen strategi adalah seni dan pengetahuan dalam merumuskan, mengimplementasikan, serta mengevaluasi keputusan-keputusan lintas fungsional yang memungkinkan sebuah organisasi untuk mencapai tujuan (David, 2011:6).

Lingkungan eksternal mencakup lingkungan umum (makro) dan juga lingkungan industri. Untuk lingkungan makro digunakan Analisa PESTEL yaitu Political, Economic, Social, Technological, Environmental, dan Legal (Pearce, 2005). Untuk lingkungan industri, Michael E. Porter, dalam buku Competitive Strategy (1980) menyebutkan bahwa konsep mengenai lingkungan industri harus dimasukan dalam hal perencanaan suatu bisnis. Lingkungan industri termasuk ke dalam lingkungan diluar perusahaan yang sangat mempengaruhi terhadap pertumbuhan perusahaan dalam menentukan arah serta tindakan yang berpengaruh terhadap penentuan strategi bagi perusahaan

Lingkungan internal dilakukan untuk mengetahui tingkat daya saing perusahaan berdasarkan kondisi internal perusahaan. Menurut jurnal yang ditulis oleh Prahalad dan Hamel yang berjudul The Core Competence of the Corporation (1990), core competencies atau kompetisi inti merupakan sesuatu yang dimiliki oleh perusahaan yang dihasilkan dari proses penggunaan sumber daya perusahaan secara optimal, yang kemudian dari kapabilitas perusahaan untuk mengoptimalkan sumber daya perusahaam, terus dipelajari dan ditingkatkan menjadi sebuah kompetensi. Kompetensi ini dihasilkan dari kompetensi yang memenuhi kriteria VRCN (Valuable, Rare, Costly to Imitate, Non-Substitutable) yaitu merupakan kriteria dari sustainable competitive advantadge.

Dalam menentukan rancangan bisnis model, akan digunakan analisis Matriks SWOT (Rangkuti, 2002:18) menjelaskan bahwa analisis SWOT adalah identifikasi berbagai faktor secara sistematis untuk merumuskan strategi perusahaan. Analisis ini didasarkan pada logika yang dapat memaksimalkan kekuatan (strengths) dan peluang (opportunities), namun secara bersamaan dapat meminimalkan kelemahan (weakness) dan ancaman (threats) dan juga analisa tentang strategi bersaing (competitive strategy atau disebut juga Porter's Five Forces dimana Michael A. Porter memperkenalkan 3 jenis strategi generik, yaitu: Keunggulan Biaya (Cost Leadership), Pembedaan Produk (Differentiation), dan Focus.

Osterwalder dan Pigneur (2012) mengatakan bahwa model bisnis dapat dijelaskan dengan sangat baik melalui sembilan balok bangun dasar yang memperlihatkan cara berfikir tentang bagaimana cara perusahaan menghasilkan uang. Sembilan balok bangun tersebut diletakkan pada sebuah susunan yang disebut Business Model Canvas. Business Model Canvas terbagi menjadi sembilan bagian utama, yaitu: Customer Segments (Segmen Pelanggan), Value Propositions (proposisi nilai), Channel (Saluran), Customer Relationships (Hubungan Pelanggan), Revenue Streams (Arus Pendapatan), Key Resources (Sumber Daya 
Utama), Key Activities (Aktivitas Kunci), Key Partnerships (Kemitran Utama) dan Cost Structure (Struktur Biaya).

\section{Gambaran Umum}

PT. XYZ adalah perusahaan yang memberikan total solusi ICT kepada komunitas logistik di Indonesia. PT XYZ didirikan pada tanggal 21 September 2012 oleh 2 (dua) BUMN ternama. Visi Perusahaan adalah menjadi penyedia solusi digital terkemuka di industri kepelabuhanan dan Logistik Maritim di Indonesia adalah visi dari PT XYZ. Misi Perusahaan yaitu Meningkatkan daya saing ekonomi Indonesia melalui sistem modern dan terintegrasi dengan standar layanan kelas dunia, Menghubungkan komunitas logistik melalui platform dan proses digital tepercaya, dan memberikan nilai tambah kepada pemegang saham.

Strategi Perusahaan fokus kepada 3S (Seaport, Shpping, Society) dan 3T (Terminal, Trade, Transport), PT XYZ membagi layanan dan jasa produk nya menjadi 4 portfolio utama yaitu Digital Seaport Solution, e-Payment Service, Supply Chain Management Service, dan ICT System Implementor. Dalam kurun waktu lima tahun ini, PT XYZ fokus kepada projectproject digitalisasi Pelabuhan-pelabuhan di Indonesia, khususnya Pelabuhan yang dikelola oleh PT Pelindo II (Persero)

\section{Metode Penelitian}

Jenis penelitian didalam tesis ini adalah studi kasus. Penelitian dilaksanakan dengan mengumpulkan data-data di lapangan mulai dari Januari 2018. Sumber dan Pengumpulan DataStudi kasus ini menggunakan metode penelitian gabungan dari penelitian lapangan (field research) dan kepustakaan (desk research). Jenis kasus untuk PT XYZ merupakan studi kasus perusahaan (company case).

Studi kasus ini akan melihat dari sudut pandang perusahaan PT XYZ dimana alur yang digunakan adalah alur maju ketika PT XYZ sebagai salah satu penyedia ICT di Indonesia, di tuntut untuk dapat menghasilkan model bisnis baru yang efektif dan inovatif dalam hal untuk meningkatkan pangsa pasar yang semakin luas dan terbuka.

\section{Metode Analisa}

Metode analisis data dalam studi kasus ini menggunakan metode analisis kualitatif, dimana data dan informasi yang didapatkan baik berupa data primer dari PT XYZ maupun data sekunder akan diolah dan di analisis.

\section{ANALISA DAN PEMBAHASAN}

Hasil analisa peluang yang dimiliki PT XYZ yaitu adanya pertumbuhan yang masih cukup tinggi di sektor logistik dan kemaritiman, baik nasional maupun regional; tren Pelabuhan yang mengarah kepada Digital Seaport; kebutuhan yang cukup tinggi dalam hal pemanfaatan teknologi (khususnya Intenet of Things, IoT) di industri logistik dan serupa.

Hasil Analisa terkait ancaman yang dapat di identifikasi untuk PT XYZ yaitu adanya kemudahan bagi pesaing dan pendatang baru untuk masuk dan menawarkan layanan dan solusi serupa; tenaga ahli IT yang bersertifikasi yang dapat dengan mudah berpindah perusahaan atau industri; Life cycle teknologi semakin cepat.

Hasil Analisa terkait kekuatan yang dimiliki PT XYZ yaitu merupakan anak usaha dari dua BUMN besar yang memiliki kompetensi di bidang masing-masing; memiliki dukungan sumber daya teknologi mutakhir; memiliki dukungan infrastruktur yang mutakhir; kompetensi dan kapabilitas organisasi dalam bidang pengembangan aplikasi dan implementasi teknologi digital yang cukup tinggi. 
Hasil Analisa tentang kelemahan yang perlu diperbaiki oleh PT XYZ yaitu masih berfokus pada penetrasi pasar dilingkungan PT Pelabuhan Indonesia II (Persero); belum semua produk dapat penetrasi keluar dari PT Pelabuhan Indonesia II (Persero); perencanaan kepegawaian belum tersusun secara sistematis dan turn-over Pegawai masih tinggi.

Berikut gambaran matriks SWOT PT XYZ:

\begin{tabular}{|c|c|c|}
\hline Situasi Internal & STRENGTHS (KEKUATAN) & WEAKNESSES (KELEMAHAN) \\
\hline Situasi Eksternal & $\begin{array}{l}\text { S1. Anak perusahaan } 2 \text { BUMN besar } \\
\text { S2. Teknologi mutakhir } \\
\text { S3. Infrastruktur mutakhir } \\
\text { S4. Kompetensi pengembangan aplikasi } \\
\text { S5. Kompetensi implementasi teknologi digital }\end{array}$ & $\begin{array}{l}\text { W1. Pangsa pasar fokus di perusahaan induk } \\
\text { W2. Produk terbatas } \\
\text { W3. Turn over tinggi }\end{array}$ \\
\hline OPPORTUNITIES (PELUANG) & STRATEGI SO & STRATEGI WO \\
\hline $\begin{array}{l}\text { O1.Pertumbuhan sektor logistik } \\
\text { O2. Pertumbuhan sektor maritim } \\
\text { O3.Tren Digital Seaport } \\
\text { O4.Tren Internet of Things }\end{array}$ & $\begin{array}{l}\text { S01. Inisiasi Market Place Port \& Logistics } \\
\text { S02. Menggiatkan pemasaran } \\
\text { S03. Masuk ke area Supply Chain dan Logistics } \\
\text { SO4. Workshop dengan asosiasi } \\
\text { SO5. Deployment Digital Port }\end{array}$ & $\begin{array}{l}\text { WO1. Meningkatkan anggaran penelitian dan pengembangan } \\
\text { produk } \\
\text { WO2. Perencanaan kepegawaian sistematis } \\
\text { WO3. Pengembangan SLA dan Manage Service } \\
\text { WO4. Mass Solution/ Market Penetration ke Segmen di luar } \\
\text { BUMN }\end{array}$ \\
\hline THREATS (ANCAMAN) & STRATEGI ST & STRATEGI WT \\
\hline $\begin{array}{l}\text { T1. Bertambahnya perusahaan start up } \\
\text { T2. Pindahnya tenaga ahli ke perusahaan sejenis } \\
\text { T3. Pendeknya life cycle teknologi }\end{array}$ & $\begin{array}{l}\text { ST1. Joint Development untuk specific solution \& market } \\
\text { penetration } \\
\text { ST2. Empowerment karyawan } \\
\text { ST3. Peningkatan corporate branding } \\
\text { ST4. Peningkatan tenaga ahli internal } \\
\text { ST5. Penguatan budaya perusahaan } \\
\text { ST6. Peningkatan seamless \& automation prosess }\end{array}$ & $\begin{array}{l}\text { WT1. Inovasi produk } \\
\text { WT2. Peningkatan aspek compliance } \\
\text { WT3. Menetapkan business model yang sustainable } \\
\text { WT4. Partnership dengan mitra yang handal } \\
\text { WT5. Penataan sistem rekrutmen }\end{array}$ \\
\hline
\end{tabular}

Berdasarkan hasil penelitian melalui wawancara langsung, terutama kepada jajaran direksi dan Manager Corporate and Planning Secretary, PT XYZ menerapkan strategi fokus diferensiasi, strategi ini fokus pada pengembangan produk yang menawarkan nilai lebih dan keunikan produk yang tidak dimiliki kompetitor.

Analisis SWOT terhadap 9 blok bangunan bisnis kanvas untuk PT XYZ:

\begin{tabular}{|c|c|c|c|c|c|}
\hline No & ASPECTS & STRENGTH & WEAKNEESS & OPPORTUNITY & THREATS \\
\hline 1 & Customer Segment & Didukung Sinergi BUMN & $\begin{array}{l}\text { Belum fokus kepada pasar di } \\
\text { luar grup perusahaan }\end{array}$ & $\begin{array}{l}\text { Sektor industri logistik di } \\
\text { luar pelabuhan, semakin } \\
\text { menuju ke arah } \\
\text { digitalisasi/automasi }\end{array}$ & $\begin{array}{l}\text { Hadirnya perusahaan IT yang } \\
\text { masuk ke sektor pelabuhan }\end{array}$ \\
\hline 2 & $\begin{array}{l}\text { Value } \\
\text { Propositions }\end{array}$ & $\begin{array}{l}\text { Teknologi mutakhir digital } \\
\text { Port \& Logistic }\end{array}$ & $\begin{array}{l}\text { Jumlah produk yang di } \\
\text { release ke pasar terbatas }\end{array}$ & $\begin{array}{l}\text { Kebutuhan integrasi } \\
\text { teknologi antar stakeholders } \\
\text { kepelabuhanan }\end{array}$ & $\begin{array}{l}\text { Pesaing mulai meniru solusi } \\
\text { yang ditawarkan oleh PT } \\
\text { XYZ }\end{array}$ \\
\hline 3 & Channels & $\begin{array}{l}\text { Dukungan Telkom Group dan } \\
\text { IPC Group }\end{array}$ & $\begin{array}{l}\text { Belum mengoptimalkan } \\
\text { berbagai channels yang } \\
\text { telah dimiliki }\end{array}$ & $\begin{array}{l}\text { Tingginya kebutuhan digital } \\
\text { solusi dari pelanggan- } \\
\text { pelanggan group perusahaan }\end{array}$ & $\begin{array}{l}\text { Anak perusahaan Telkom } \\
\text { yang memberikan solusi } \\
\text { serupa }\end{array}$ \\
\hline 4 & Customer Relation & $\begin{array}{l}\text { Dukungan dari Asosiasi } \\
\text { Kepelabuhanan dan Logistik } \\
\text { di Indonesia }\end{array}$ & $\begin{array}{l}\text { Jumlah Account Manager } \\
\text { masih terbatas }\end{array}$ & $\begin{array}{l}\text { Besarnya peluang yang ada } \\
\text { di grup perusahaan }\end{array}$ & $\begin{array}{l}\text { Jika ada Account Manager } \\
\text { yang pindah ke perusahaan } \\
\text { sejenis. }\end{array}$ \\
\hline 5 & Revenue Stream & $\begin{array}{l}\text { Mendapat hak khusus untuk } \\
\text { penunjukan langsung pada } \\
\text { project-project di Grup } \\
\text { Perusahaan }\end{array}$ & $\begin{array}{l}\text { Masih tergantung kepada } \\
\text { project-project dari parent } \\
\text { company }\end{array}$ & $\begin{array}{l}\text { Meningkatnya kebutuhan } \\
\text { manage service di industri } \\
\text { kepelabuhanan terhadap } \\
\text { sektor IT }\end{array}$ & $\begin{array}{l}\text { Produk serupa yang mulai } \\
\text { muncul di industri logistik }\end{array}$ \\
\hline 6 & Key Resources & $\begin{array}{l}\text { Tenaga ahli IT yang } \\
\text { tersertifikasi }\end{array}$ & $\begin{array}{l}\text { Tergantung kepada teknologi } \\
\text { yang dikembangkan oleh } \\
\text { parent company }\end{array}$ & Teknologi yang selalu update & $\begin{array}{l}\text { Turn over tinggi untuk } \\
\text { tenaga ahli IT yang dimiliki }\end{array}$ \\
\hline 7 & Key Activity & $\begin{array}{l}\text { Kompetensi implementasi } \\
\text { teknologi digital }\end{array}$ & $\begin{array}{l}\text { Untuk digitalisasi di sektor } \\
\text { logistik di luar pelabuhan, } \\
\text { portofolio perlu ditingkatkan }\end{array}$ & $\begin{array}{l}\text { Belum semua sektor logistik } \\
\text { telah digital proses }\end{array}$ & $\begin{array}{l}\text { Munculnya perusahaan } \\
\text { digital dengan solusi yang } \\
\text { ditawarkan serupa }\end{array}$ \\
\hline 8 & Key Partners & $\begin{array}{l}\text { Bagian dari International } \\
\text { Port Community System } \\
\text { Association }\end{array}$ & $\begin{array}{l}\text { Level partnership dengan } \\
\text { beberapa principal, belum } \\
\text { level yang terbaik }\end{array}$ & $\begin{array}{l}\text { Bisnis partner yang dapat } \\
\text { meningkatkan pangsa pasar }\end{array}$ & $\begin{array}{l}\text { Pesaing mempunyai level } \\
\text { partnership yang lebih baik } \\
\text { dengan principal }\end{array}$ \\
\hline 9 & Cost Structure & $\begin{array}{l}\text { Dukungan pembiayaan modal } \\
\text { dari Parent companies }\end{array}$ & $\begin{array}{l}\text { Beban biaya bahan mitra } \\
\text { terlalu tinggi }\end{array}$ & $\begin{array}{l}\text { Program Vendor } \\
\text { management dapat } \\
\text { menurunkan biaya mitra yang } \\
\text { terlalu tinggi }\end{array}$ & $\begin{array}{l}\text { Kesalahan perhitungan biaya } \\
\text { project management }\end{array}$ \\
\hline
\end{tabular}

Rekomendasi bisnis model kanvas untuk PT XYZ: 


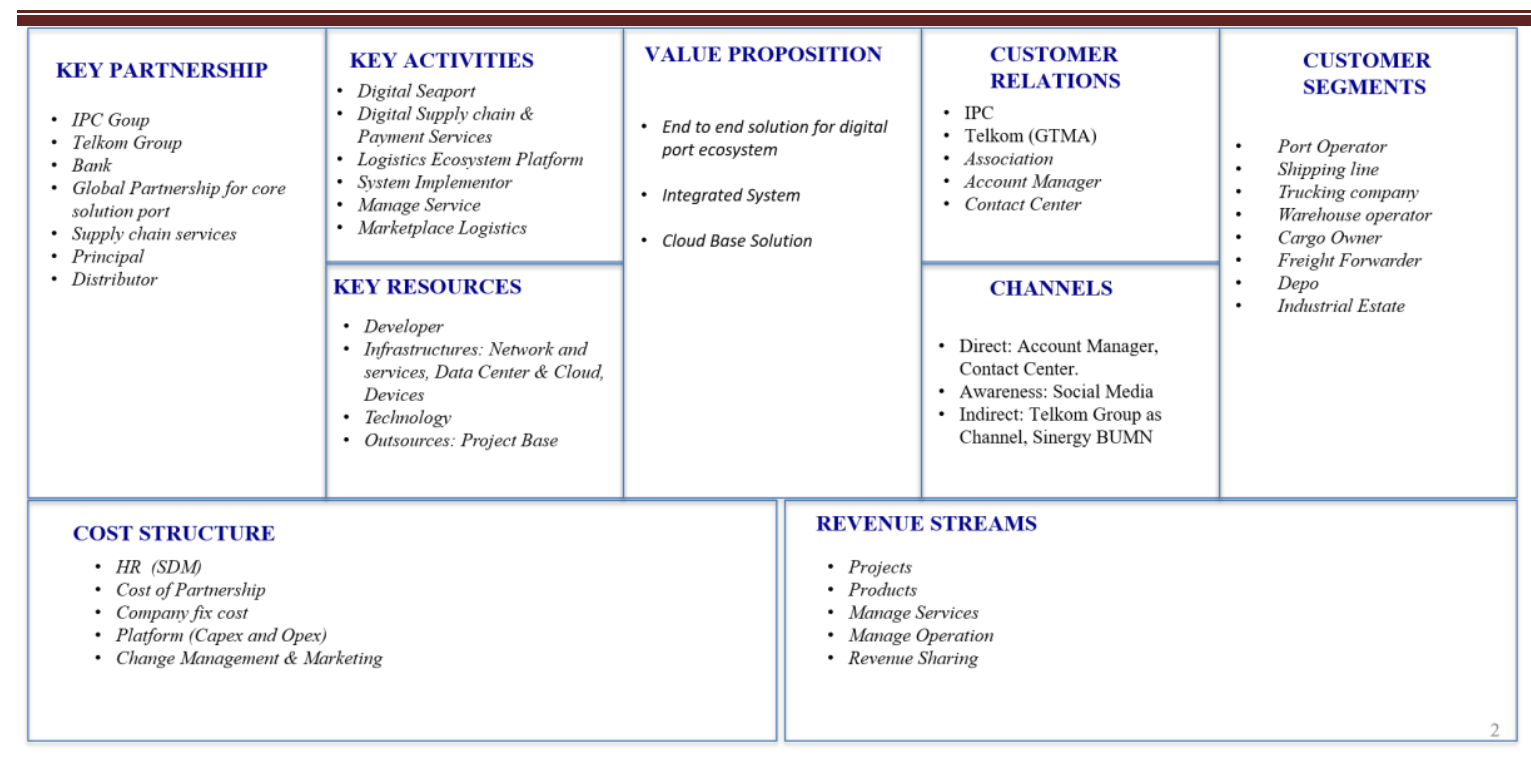

\section{Penutup}

\section{KESIMPULAN}

Berdasarkan hasil penelitian, PT XYZ memiliki peluang karena beberapa hal, yaitu pertumbuhan yang masih cukup tinggi di sektor logistik dan kemaritiman, tren Pelabuhan kepada Digital Seaport. Selain itu ada ancaman yang perlu diwaspadai, seperti kemudahan bagi pesaing dan pendatang baru untuk masuk dan menawarkan layanan dan solusi serupa, tenaga ahli IT bersertifikasi yang dapat dengan mudah berpindah perusahaan atau industri, Life cycle teknologi semakin cepat. Dari sisi kekuatan, PT XYZ memiliki beberapa keunggulan, yaitu sebagai anak usaha dari dua BUMN besar, dukungan sumber daya teknologi \& infrastruktur mutakhir, kompetensi dan kapabilitas organisasi dalam bidang pengembangan aplikasi dan implementasi teknologi digital. Tetapi di sisi lain, ada kelemahan yang harus diperbaiki yaitu masih berfokus pada penetrasi pasar dilingkungan PT Pelabuhan Indonesia II, belum semua produk dapat penetrasi di pasar logistik, perencanaan kepegawaian belum tersusun secara sistematis dan turn-over Pegawai masih tinggi. Dari analisis matrik SWOT dan strategi generic Porter, PT XYZ menerapkan strategi fokus diferensiasi. Strategi ini fokus pada pengembangan produk yang menawarkan nilai lebih dan keunikan produk yang tidak dimiliki kompetitor.

\section{Saran}

Beberapa saran yang dapat penulis sampaikan yaitu PT XYZ mulai melakukan penetrasi pasar diluar IPC group dengan menawarkan pola bisnis model baru seperti bagi hasil dan manage operation. Memperkaya dan meningkatkan partnership dengan mitra lokal maupun mitra global yang terpercaya di bidang Pelabuhan dan logistik maritim, peningkatan tenaga ahli IT tersertifikasi dan pemberdayaan karyawan, inovasi produk sesuai dengan tren kebutuhan teknologi saat ini, seperti IoT dan blockchain system serta melakukan penataan sistem rekrutmen dan penguatan budaya perusahaan.

\section{DAFTAR PUSTAKA}

David, Fred R., (2011). Strategic Mangement Manajemen Strategi Konsep. Edisi 12. Jakarta: Salemba Empat.

Rangkuti, F. (2006). Analisis SWOT Teknik Membedah Kasus Bisnis, cetakan ke-13. Jakarta: Gramedia Pustaka Utama.

Osterwalder, A., and Y. Pigneur. (2010). Business Model generation. New York: John Wiley $\&$ Sons. 
Pierce, II, J.A., dan Robinson, Jr., R.B., 2008, Manajemen Strategis-Formulasi, Implementasi, dan Pengendalian, edisi 10,, Jakarta: Salemba Empat.

Porter, Michael. (2007). Strategi Bersaing Teknik Menganalisis Industri Dan Pesaing. Jakarta: Erlangga.

Porter, M.E., (2008). The Five Competitive Forces that Shape Strategy, Harvard Business Review, Vol.86.

Rangkuti, F. (2006). Analisis SWOT Teknik Membedah Kasus Bisnis, cetakan ke-13. Jakarta: Gramedia Pustaka Utama.

Rangkuti, F. (2006). Analisis SWOT Teknik Membedah Kasus Bisnis, cetakan ke-13. Jakarta: Gramedia Pustaka Utama. 
